\title{
Exploration of barriers to the uptake of nutritional services among adolescent girls from the rural communities of Tigrai Region, Northern Ethiopia: A qualitative study
}

Amaha Kahsay ( $\square$ amahakahsay@gmail.com )

Mekelle University https://orcid.org/0000-0002-6242-8040

Hadush Gebregziabher

Mekelle University

Znabu Hadush

Mekelle University

Dejen Yemane

Mekelle University

Abebe Hailemariam

UNICEF

Afework Mulugeta

Mekelle University

\section{Research}

Keywords: Adolescent girls, barriers, nutritional services, rural, Tigrai, Ethiopia.

Posted Date: January 22nd, 2020

DOI: https://doi.org/10.21203/rs.2.21602/v1

License: (c) (i) This work is licensed under a Creative Commons Attribution 4.0 International License.

Read Full License 


\section{Abstract}

Introduction:Adolescence is a time of tremendous physical growth and mental development, with high nutrient requirements. Ethiopia is among a country with high prevalence of nutritional deficiencies among the women of reproductive age group whilst adolescent girls from rural suffer from it disproportionally. However, there is dearth of evidence regarding the barriers that hinder adolescent girls to utilize the available nutritional interventions. Therefore, the current study aimed to qualitatively explore the range of barriers for the uptake of nutritional interventions among adolescent girls in rural communities of Tigrai, Northern Ethiopia. Methods and participants : An explorative qualitative study was employed among purposively selected adolescent girls and school teachers form rural districts of Tigrai region of Northern Ethiopian. Nine focused group discussions (FGDs) with adolescent girls (Five with in-school adolescents and four with out-school girls), thirteen in-depth interviews with adolescent girls (Seven in-school girls and six out-school girls) and in-depth interviews with six teachers were conducted using semi-structured guide. Data were audio-taped, transcribed verbatim in local language, translated into English and imported into ATLAS.ti version 7.5 qualitative data analysis software for coding and analysis. Results : Adolescents perceived that stunting, anemia and thinness are among the main nutritional problems in their community. Food insecurity, limited nutrition awareness in the community, limited access to water for drinking and gardening, high workload, service provider's little attention for adolescents' nutrition and food taboo were emerged as barriers for the uptake of adolescent girls nutritional interventions. Though limited in reach, available nutritional interventions include awareness creation, nutritional supplementation, and disease prevention. Conclusion : A range of barriers hinder adolescent girls to access nutritional interventions. Food insecurity poses a strong challenge to adolescent girls' nutrition. As access to safe drinking water continues to be a considerable bottleneck for nutritional interventions, multi-sectoral response to integrate water, sanitation and hygiene (WASH) services is required. Bounded by food taboo, high burden of workload among the adolescent girls, women empowerment and nutritional status seem to be the unfinished agenda in resource limited settings such as the rural areas of Tigrai, Northern Ethiopia. Keywords : Adolescent girls, barriers, nutritional services, rural, Tigrai, Ethiopia.

\section{Background}

Adolescence, which refers to age of 10 to 19 years, is the period of tremendous growth and development that begins at puberty and ends in early adulthood. About $20 \%$ of final adult height, $45 \%$ of increments in bone mass and $50 \%$ of the adult weight are attained in this period [1], which requires rapid tissue expansion with special nutrient requirements, including amino acids for growth of striated muscle, as well as calcium and vitamin $D$ to accommodate bone growth [2,3]. Today, 1.2 billion individuals are in adolescent age group whilst nine out of the ten live in the developing world with higher likelihood to face profound nutritional challenges in their process of growth and development [4].

Considerable nutritional problems attributed to inadequate diet continues to turns out to poor health status during adolescent and sizable development challenges in developing countries. Fewer than $2 \%$ of adolescents consume adequate amounts of all the food groups, and almost $20 \%$ of females and $7 \%$ of 
males do not consume an adequate number of portions of any of the food groups [5].The global prevalence of underweight (thinness) among adolescents is, $8.4 \%$ for girls and $12.4 \%$ in boys which indicated that prevalence has not declined much in the past three decades [6]. Nevertheless, Adolescents often are not aware of the potential health risks associated with poor habits and have not thought about making dietary changes [7]. On the other side, global adolescent obesity rates for both males and females were reaching $6.5 \%$ and $4.7 \%$ respectively [8], while the prevalence for both sexes raises up to $8 \%$ in Ethiopia [9].

Backed to the set of socio-cultural, economic and gender related factors, previous studies from Ethiopia show that risk of malnutrition is higher among adolescents' girls. In Ethiopia, twenty-two percent of women aged 15-49 years are thin (with BMI less than 18.5) [9]; whereas, $26.5 \%$ and $58.3 \%$ adolescents in Tigrai, are stunted and thin, respectively [1]. A recent meta-analysis from Ethiopia also shows a high pooled prevalence of stunting $(20.7 \%)$ and underweight (27.5\%) among adolescent girls in Ethiopia [10] where as a school based study shows high prevalence of thinness (29\%) [11]. Moreover, adolescents from rural settings, higher family size, with unprotected water source for drinking and food insecure household are with greater odds of the nutritional problems [10, 12]. As literature depicts, nutritional outcomes of adolescents have been determined by several factors like adolescent pregnancy, advertisements, watching television during mealtime, socio-economic status of parents, gender disparity, activity-related health behavior, skipping a meal, and high consumption of sweets and soft drinks containing sugar and others [13-27]. In this case, nutrition-related interventions to adolescents have been undergone mainly in developed nations in response of the aforementioned and other related factors; of which, relatively successful nutrition interventions are culturally appropriate and tailored educational programs [18, 22, 28-30), using school-based health and nutrition intervention [31, 32], and lifestyle (nutrition education and physical activity) and nutrient supplementation interventions [33, 34]. However, in most developing countries, nutrition initiatives have been focusing on children and women, thus neglecting adolescents [35]. Likewise, in Ethiopia there are community-based interventions mainly to prevent malnutrition in women and children; however, there is limited effort to address malnutrition in adolescents [36].

Moreover, Tigrai regional state of Ethiopia is among the region with higher prevalence of adolescent stunting and thinness, which are $26.5 \%$ and $58.3 \%$, respectively [1]. Cognizant to the fast growth during adolescence, girls are particularly vulnerable to malnutrition as array of socio-cultural factors restrict their food consumption, for example, as literature shows there is association between avoiding foods for cultural beliefs that endangers the health status and leads to nutritional deficiencies like anemia [37-39]. Despite the global and national initiatives to improve the health and welling of adolescent girls, they are a near miss to many of the nutritional interventions as most of the interventions are concentrated on pregnant and lactating women (PLW), and children. Understanding the available nutritional services targeted for adolescent girls (if any) residing in resource limited settings and exploring the socio-cultural barriers for the services would be worthwhile to underpin evidence-based solution. Therefore, the current study aimed at exploring the barriers for the uptake of nutritional services among adolescent girls in resource limited settings of rural Tigrai Region, Northern Ethiopia. 


\section{Methods And Participants}

\section{Study Setting}

The study was conducted among adolescent girls from five districts (Ofla, Samre Seharti, Laelay Maichew and Medebay Zana) of Tigrai region of Ethiopia. Data was collected from November 2017 through January 2018. The details of the methodology are described elsewhere [40].

\section{Study design}

A community and institution-based exploratory qualitative study was conducted to explore barriers for nutritional interventions among adolescent girls in rural Tigrai of Ethiopia.

\section{Sampling and Participants}

Purposively selected participants were approached for focused group discussions (FGDs) and in-depth interview. Nine focused group discussions (FGDs) with adolescent girls (Five with in-school adolescents and four with out-school girls), twelve in-depth interviews with adolescent girls (Seven in-school girls and five out-school girls) and in-depth interviews with seven teachers were conducted. Participants were selected from two kebeles (smallest administrative units) of each of the five districts. Eight to ten participants were purposively selected for each FGD.

\section{Data Collection Tools and procedure}

Semi-structured discussion and interview guides were developed by a team consisting of experts from multi-disciplinary areas, namely public health, agriculture, nutrition, health promotion and food science. The guides covered existing nutrition platforms for nutrition services and barriers to the uptake of nutrition services for adolescent girls.

Focus group discussions (FGDs) among schools for in-school students and the teacher by preparing a setting where privacy is kept and recording is possible with little disturbance Discussions were conducted in a circular seating facilitated each FGD. Data were audio-taped, and transferred to personal computer where access to nobody out of the investigators is denied. Audio-taped files were transcribed verbatim using the local language (Tigrigna) and translated to English. Each transcript was made ready for analysis.

Each collected data were transcribed before the next data is being collected, which enables to capture emerging insights into the semi-structure guide. Investigators believed this helped to enhance the credibility and comprehensiveness of the insights. Peer debriefing was undertaken during the data collection and coding on daily based as means of improving trustworthiness on the data. Moreover, triangulation data generated from FGDs and in-depth interviews were applied.

\section{Data availability statements}


The datasets used and/or analyzed during the current study are available from the corresponding author on reasonable request.

\section{Data analysis}

Data collection and preliminary coding were conducted Transcripts were imported into ATLAS.ti version 7.5 qualitative data analysis software. Two investigators openly coded the data independently and a daily based peer debriefing was held to assess and discuss similarities and differences in coding the transcripts. A third investigator was invited for resolution if disagreements encountered between the coders. Similar codes were grouped into categories that link the codes. Then, categories were emerged into themes in reference to the study objectives. Reports were written using descriptions and elaborative quotes.

\section{Result}

An average number of eight adolescent girls (ranged from 8 to 10) participated in each FGD. The age of participants in the focused group discussion and in-depth interviews ranged from 14 to 19 years. School teachers from primary schools were interviewed to complement information provided by the adolescent girls (Table 1$)$.

Table 1: Description of groups study participants per district, in rural communities of Tigrai Region, Ethiopia, 2017/18

\begin{tabular}{|l|c|c|c|c|c|}
\hline District & \multicolumn{2}{|c|}{ Number of FGDs } & \multicolumn{3}{c|}{ Number of IDIs } \\
\hline & In-school & Out of school & In-school & Out-school & School Teacher \\
& & & & & 2 \\
\hline Ofla & 1 & 2 & 4 & 1 & 2 \\
\hline Seharti Samre & 1 & - & 1 & 1 & 1 \\
\hline Tanqua Abergele & 1 & 1 & 1 & - & 1 \\
\hline Lealay machew & 1 & - & 1 & 2 & 1 \\
\hline Medebay Zana & 1 & 1 & - & 1 & $\mathbf{7}$ \\
\hline Total & 5 & $\mathbf{4}$ & $\mathbf{7}$ & $\mathbf{5}$ & \\
\hline
\end{tabular}

FGDs: Focus Group Discussions, IDIs: In Depth Interviews

\section{Perceived nutritional problems among adolescents girls}

Participants were asked to describe their perception regarding the nutrition related issues among adolescent girls in their community. Shortness, anemia and thinness were the most frequently discussed nutritional problems with varieties of opinions and reflections. As indication of presence of stunting among adolescent girls, participants frequently mentioned that there are adolescent girls who are with short stature in their locality. It is well mentioned by in-school adolescent girl: 
There are adolescents their height is short as compared to their age [...] [15 years_in-school_ofla district].

Though the above opinion was predominantly reported, few adolescent girls also differently mentioned that short stature is not common in their locality. An adolescent girl from Hakfen reflected:

I have not seen stunted adolescents in this community up to date. [...]. No adolescent is admitted due to malnutrition. I never encounter such case [14 years, out of school girl].

Regarding the presence of stunting, some others also reported that the possibility of finding short adolescent girl for age in the locality is becoming less nowadays as dietary habit is getting improved. This opinion is captured in the following quotes:

When we see in adolescents, though most of them are ok, there are some that are short or small-sized. Generally speaking, it is good from the earlier times in terms of nutrition and others issues in nowadays. The situation is changed nowadays. [... ] However, the presence of thin and short adolescents currently may shows that there is an incidence of the problem [17 years old, completed $8^{\text {th }}$ grade].

A school teacher also forwarded similar reflection:

As compare to the previous one, the risk of exposure to malnutrition is low now. The feeding habit of the community is extremely changed now (23 years aged, Samre woreda).

Participants also specified their perception regarding the causes of shortness (stunting)as the result of; (1) Heredity/genetic factors of from parents; (2) Mother's inadequate feeding, (3) Adolescent girls' inadequate feeding, (4) Disease or Illness (5) carrying heavy objects in reference to their age. Extensive, strong and repeated reflections that favor and disfavor hereditary/genetic and dietary reasons were repeatedly raised as perceived reasons of stunting. Participants reflected that if either the mother or the father or both are short stature, they may give offspring with short stature. In this view, participants considered shortness of the girls as natural, hence, acceptable and normal status. Opinions that favor dietary reasons to hereditary/genetic reasons argued that diet is the foundation of health in reference to the nutrient demanding age of adolescence (see Table 2).

Table 2: Perceived reasons and elaborative quotes of stunting among adolescent girls, in rural communities of Tigrai Region, Ethiopia, 2017/18 


\begin{tabular}{|c|c|c|}
\hline $\begin{array}{l}\text { Perceived } \\
\text { reasons }\end{array}$ & Descriptions & Elaborative quotes \\
\hline $\begin{array}{l}\text { Parents' } \\
\text { Heredity/genetic } \\
\text { factors }\end{array}$ & $\begin{array}{l}\text { One's height } \\
\text { has no } \\
\text { relation with } \\
\text { diet but with } \\
\text { the parents } \\
\text { genetic factor }\end{array}$ & $\begin{array}{l}\text {-"[...] this is due natural process; if God creates you, } \\
\text { you will be longer [taller] if not you will be short; this } \\
\text { is not related to nutrition [...] [FGD-School } \\
\text { Adolescent_Keyih-Emba Kebele_Samire woreda]. } \\
\text {-For height it is natural; itis not related with nutrition } \\
\text { but when we come to weight the one who feeds } \\
\text { properly will increase his weight with his age. [12 } \\
\text { years old, in-school girl, Samre district] }\end{array}$ \\
\hline $\begin{array}{l}\text { Mother's } \\
\text { inadequate diet }\end{array}$ & $\begin{array}{l}\text { Inadequate } \\
\text { diet before or } \\
\text { during } \\
\text { pregnancy } \\
\text { yields short } \\
\text { offspring }\end{array}$ & $\begin{array}{l}\text { The stunted ones are because their mother did not eat } \\
\text { a balanced diet while she was pregnant [...] } \\
\text { [IDI_School Teacher_Lemlem kebele_Samre woreda]. }\end{array}$ \\
\hline $\begin{array}{l}\text { Adolescent's } \\
\text { inadequate diet }\end{array}$ & $\begin{array}{l}\text { If adolescent } \\
\text { girls do not } \\
\text { eat adequate } \\
\text { and balanced } \\
\text { diet, they will } \\
\text { get stunted }\end{array}$ & $\begin{array}{l}\text { - In my view, it is caused due to the shortage of foods. } \\
\text { If somebody doesn't feed properly, s/he becomes thin } \\
\text { and short.[18-year-old, } 10^{\text {th }} \text {-grade-completed, Tankua- } \\
\text { Abergele-district] } \\
\text {-Feeding style is the base for our health. Therefore, the } \\
\text { adolescents are ready for becoming adult, and then if } \\
\text { they fail to feed appropriately, they may develop } \\
\text { various health problems and fail to grow as needed } \\
\text { [School-Teaher, Laelay-Maychew] }\end{array}$ \\
\hline $\begin{array}{l}\text { Disease or } \\
\text { Illness }\end{array}$ & $\begin{array}{l}\text { Disease } \\
\text { during or } \\
\text { before } \\
\text { adolescence } \\
\text { causes } \\
\text { stunting }\end{array}$ & $\begin{array}{l}\text { There may be naturally short girls due to disease [19- } \\
\text { years, Out of school, Samre district]. } \\
\text { There are also naturally stunted adolescents due their } \\
\text { illness[17-years, } 7^{\text {th }} \text { grade, Samre district] }\end{array}$ \\
\hline Workloads & $\begin{array}{l}\text { Adolescent } \\
\text { girls with } \\
\text { high } \\
\text { workload are } \\
\text { at high risk of } \\
\text { short stature. }\end{array}$ & $\begin{array}{l}\text { Adolescents who have high workload without getting } \\
\text { balanced diet will be very short. A ten years-old } \\
\text { adolescent who do not have much workload will be } \\
\text { even longer than the twenty years-old girls who have } \\
\text { high workload [18-years-old, Out of school Tankua- } \\
\text { Abrgele-district]. }\end{array}$ \\
\hline
\end{tabular}


Participants reported that anemia is evident in their locality being adolescent girls at higher risk next to pregnant women. Although school girls claimed for irregularity and interruption, school-based folic acid supplementation was provided as nutritional intervention to prevent anemia. The following quote captured existence anemia among adolescents,

[...] anemia is common among us (adolescents) and pregnant women [...] [14 years_in-School_Samire woreda].

Differently, an out-school girl and a school teacher in Medebay zana district reported that anemia is not a concern of adolescents girls.

I do not think there are adolescents with Anaemia. There is education and they are eating balance diet. Therefore, there is no Anaemia [16 years, out-school, Medebay Zana district].

Before pregnancy anemia is not that much so it is not a problem, but it becomes a problem during pregnancy [32 years old, School teacher, Medebay Zana district].

Participants repeatedly mentioned that poor balanced diet, high workload and food shortage are the main risk factors for anemia among adolescent girls. They specified that missing breakfast, long working hours under the sun, not eating "blood substituting" vegetables including carrot and red potato, as well as cereals yields to anemia. The following quotes elaborated participants' perceived causes of anemia,

Anaemia is caused by not eating a balanced diet [16 years-in-School_MedebayZanaworeda].

Anemia is caused as the result of high workload and poor feeding among the communities [18 years, outschool, Tankua Abergele district].

Next to stunting and anemia, participants also specified presence of thinness among adolescent girls, while only few participants raised presence of vitamin deficiencies and overweight in their locality among girls. Unlike in the case of stunting, almost all participants except one agreed that thinness is the result of inadequate diet. According to the participants' opinion, adolescent girls from households with food shortage are likely to be thin. An in-school girl captured it as follows.

There are adolescents who are short compared to their age. This could be due to their nature because sometimes there are short adolescents even if they are well nourished. However, those adolescents who are very thin are due to malnutrition [15 years, $8^{\text {th }}$ grade, Ofla district].

Similarly, FGD discussant in Samre district also uncovered this reflection.

After good feeding,people can increase their weight but not their height $\left[15\right.$ years, $8^{\text {th }}$ grade, Samre district] [15 years, $8^{\text {th }}$ grade, Samre district].

Dissimilar to the others, FGD discussant in Medebay Zana reported that heredity is responsible for thinness as is for shortness, 
There are some who are thin and there are also some who are fat. There can be thin due to heredity and there are also hereditary for shortness [18 years, out-school, Medebay Zana].

Participants agreed that overweight is less common and if any it is often due to heredity. Few also mentioned that overweight is less likely among adolescent girls who reside in rural areas because they loss energy in domestic works.

\section{Barriers to adolescent nutrition services}

\section{Food insecurity}

Participants repeatedly mentioned that food insecurity in the community, where, adolescent girls live is predominate barrier to nutritional interventions for adolescent girls. The key contributing factors specified for the food insecurity were (1) Drought and lack of rainfall (2) Insufficient agricultural productivity (3)Limited diversification of the agricultural products (4) No land owned (5) Extended family size and (6) Households' extravagance.

Shortage to food access in the community attributed to absence of rainfall was strongly discussed. FGD discussants reported from Tankua Abergele uncovered that presence of drought for the three consecutive years preceding the study. They stated it as,

This year, there was no rainfall and all crops were remained dry in this community; the livestock production is also affected by the drought due to the shortage of water [18 years, out of school, Tankua Abergele district].

Insufficient agricultural productivity was evident. Pattern of participants response to the reasons for insufficient productivity were women's low agricultural productivity, husband loss due to divorce or death, husband getting elder, few men in the household who able to plough, giving land to contract and crop pests. Consequently, food shortage was reported as a common phenomenon on September and October of a year while it could be sometimes extended from May to December. This time adolescent girls suffer from this shortage because they would be neglected to get attention. The following quotes captured this reflection,

Food shortage is common in September and October. And the problem may be extended up to December in the community until they collect their harvest. This time girls may face shortage of food [23 years, school teacher, Samre district].

For example if there is shortage of food during summer the mother gives priority for their children, what can she do? Nothing! Because she need to feed do not her children first [...]. If there is shortage of food in the family, obviously we will be affected by malnutrition [14-years, in-school, Samre district].

As it is said, shortage of food occurred from May - September. The produced food is may be used up to May but it would be run out starting from May. Then shortage of food happened [16 years old, in-school, 
Tankua Abergele district].

Participants also mentioned that the limited diversification of the agricultural products hinders to food diversification to realize the intention to use diversified food, out-of-school FGD discussants in Tankua Abergele also reaches a consensus that they often eat one type of diet that is available.

Since there is a shortage of food in the community, we eat one type of food that is available in our home; for example, we eat Injera made from Sorghum for consecutive days [18 years, out-school, Tankua Abergele district].

School teacher also reflected that advice on diversified is not realized because of limited products. There are no diverse fruits and vegetables. Actually there is tomato but the other vegetable such as lettuce, Swiss chard and others are not available in the areas because the area is lowland in which diverse vegetable does not exist [23 years, school teacher, Ofla district].

Participants also raised that households' extravagance on marriage and other ceremonies yields to food insecurity, hence aggravate nutritional problems on household members including the adolescent girls. Food insecurity was also reported in households with no man to plough themselves and those who do not own land,

It is to mean those who cannot farm their land by themselves because of death of their father are suffering from shortage of food. So that they give the land to other farmer for sharing the crop produced equally therefore the amount of crop the family gets is very minimal [...][31 year old, school teacher, Lalay Maychew].

There is shortage of foods those that do not have farm lands such as youngsters that have recently established a household [17 years, out school, Medebay Zana].

As is expected, adolescent girls from households of larger family size are at higher risk of food insecurity due to high food consumption. FGD discussants uncovered this opinion,

In rural, women or mother may give 6 to 7 children this may lead to shortage of food among our family and the mother and adolescents give priority to the young one [15 years, in-school, Samre district].

Moreover, participants revealed that adolescent girls from food insecurity households are especially vulnerable for nutritional deficiencies for reasons; (1) women and adolescent girls would be left at home with insufficient food while the husband and boys could be displaced to other areas for work, (2) Adolescent girls are given less priorities in the case of food shortage (3) high workload in domestic activities (4) women in general including adolescent girls are wrongly considered threat they could stay longer with no or limited food. The following quotes captured these opinions,

The female adolescents are more suffered from the food shortage because they have more workload at home than the male adolescent. The males can generate income by going out to the town but we can't do 
so [19 Years, in-school, Samre district].

Females are always at home whether they get or not and they have no option. On the other hand, males can work outside and at least they can eat for themselves. Thus, females suffer most from nutritional problems. If they get [food] they would eat; otherwise, they sleep with empty stomach [16 years, in-school, Tankua Abergele district].

With the increasing burden of high workload for domestic activities, out-school adolescents girls were specified as the most vulnerable to nutritional deficiencies compare to in-school adolescent girls. This is strongly explained as:

The difference between the one that is out-school girl will only focus on the activities of food preparation for the family and no one considered her what she is eating and drinking [FGD-Out-of-School-adolescentHakfen kebele_Medebay Zana].

\section{Limited nutrition awareness in the community}

Participants also revealed that poor community's awareness such of mono-diet practice, selling nutritious foods to markets, gender and discrimination in feeding contributes to adolescent girls'poor nutritional status. Rural residents take their animal production, high price crops and cereals to market to buy other consumptions, which makes members of the family including the adolescents at risk of under-nutrition.

All the things like the butter and other resources are available in the rural areas but due to lack of awareness, we take the products to the urban areas to get money. [...]. There will be a deficiency of iron not because there is a shortage of foods but because we take the products to the urban areas to get money due to lack of awareness [16 years, out-of-School, Medebay Zana district].

Participants also reported that there is tendency to prioritize food for males over females in the household. Some of the participants reasoned out that it is because males involve in energy demanding labor work than females. FGD discussant from Samre stated this issue as,

[...] what is happening is that they have the perception to say let the girls stay and provide food to the boys. In case enough food is not ready, mothers provide the available food to their husband 31 years_ School teacher_Lalay-Maychew district].

An in-school girl opposed the feeding discrimination as:

"There should not be the practice of giving the "good" food types for boys/men and the remained for girls. We have to eat equally with our brothers. There should not be any feeding disparities like you have to eat this one, boys should to eat that one [14 years, in-school, Ofla district]. 
Limited access to water. Lack of access to adequate and safe water was repeatedly mentioned as a barrier for adolescent nutritional services. Many respondents witnessed that adolescent girls need to walk around three hours on foot to fetch water as FGD-discussants raised:

[...] The main problem in in our community is no water availability. It takes us three hours to fetch water. [..]. We need to spent much time to fetch water. Then, we feel tired and we miss the class [15 years_inschool_Tanqua Abergelle district].

Moreover to this, participants claimed that lack of water hindered them from practicing backyard gardening to produce nutritious foods like that of vegetables. :

The shortage of water supply is our main problem; we could be benefited from the home garden vegetables. The shortage of water is totally affected our life[18 years_out-school adolescents_TankuaAbergele district].

\section{High workload}

Participants reported that there is high burden of energy demanding workload to adolescent girls in domestic activities including fetching water. Adolescent girls are prone for nutritional deficiency because of frequent miss of breakfast. Thus, as a consequence they are unable to concentrate in class education, miss classes, concentrate less in class, and unable to perform well in academic results. Hence, a participant recommended that there has to be present equal sharing of labor at home.

We should be equally treated at home in terms of workload. For example when I make Injera or prepare food my brother should help me in bringing water and wood. In addition we have to get equal time to study without discrimination [16 years, In-school, Samire district].

\section{Service providers' little attention for adolescents' nutrition}

Participants claimed that most of nutritional interventions including counseling, awareness creation activities, nutritional supplementations, food aids and supports are focused on pregnant, lactating women and children. This is captured in FGD discussion of:

[...] because the government's attention for nutrition improvement is more skewed to the pregnant, lactating mothers and children, there is no special training in relation to nutrition improvement for adolescent girls"[18 years-out-school_Tankua Abergele district].

As a result, the participants assured that nutrition related awareness creation and life skill trainings to adolescents are very limited as supported by:

There is lack of sufficient awareness creation, and education for adolescents. There is no that much organized work to change the awareness of the adolescents. However, the education is only given by schools that may not be enough [31 years_School Teacher_Laylay-Maychew district]. 


\section{Food taboo among adolescent girls}

Hot foods (hot Injera with hot stew, hot porridge, tea, and milk, hot sauces and soup) were the most frequently mentioned categories of food as tabooed for adolescent girls. Besides, cooked liver, milk, animal testicles (sheep and goat), Ocholoni (peanut) were reported as taboo to be eaten by adolescents girls. The participants uncovered the reasons for the foods to be considered as tabooed for adolescent girls. The most frequently mentioned reason for hot and relatively high in energy, which is perceived to facilitate early physical maturity, arouse early sexual initiation. Meat, egg and milk are also prohibited for adolescent girls for similar reasons. An FGD discussant explained it:

It is not recommended for adolescent girls to not eat heated foods; for example if you want to eat porridge or soup, it should be refrigerated before our consumption. Hot foods arouse sexuality [15 years, out-school, Tankua Abergele district].

Some participants also reflected that consumption of hot foods is believed to be associated with early initiation of menses and increasing its volume. FGD discussant in Hatsebo Kebelle captured this concept as:

Yes, our mother don't allow us to drink hot like tea and soup since it facilitate the initiation of menses and increases the volume of the menses. But when I think of it is not true it doesn't has any effect [16 years, in-school, Laelay Maychew district].

Few participants also associated adolescent girls' frequent consumption of milk with probability of having beard (facial hair) like men. Besides eating egg causes difficulties (womb narrowing) during child delivery [14 years, In-school, Tankua-Abregele district].

The pattern analysis of adherence to food taboo showed that among adolescent girls are getting less strictly with time. FGD from Hatsebo captured this opinion, the adolescent girls' disobedience to the taboo,

Previously, foods like meat, egg and milk [...] were not allowed to us and our parents informed us about this issue, but now we can eat them [19 years, in-school, Laelay-Maychew district].

\section{Available Nutritional Interventions on Adolescent girls}

Awareness creation: Few participants reported that there are interventions aimed to create awareness regarding balanced diet and food diversification, iodized salt, folic acid to prevent anemia. Participants claimed that there is no nutritional screening among adolescent girls where as it is due for children, pregnant, and lactating women. FGD discussant at Felege-Hiwot, reported,

No, the nutrition screening is occurred among pregnant and lactating mothers and children; but no in adolescent girls. Accordingly, supplementations such as plump sup and plump nut are provided for 
pregnant and lactating mothers. But there is no any measurement and food supply to the adolescent girls [18 years, Out-school, Tankua-Abergele dstrict].

Nutritional Supplementation: School based nutritional supplementation were the commonly reported nutritional interventions such as iron folic acid, mass drug administration for trachoma, Vitamin A supplementation, deworming, Most of the nutritional interventions provided. However, the interventions were inconsistently reported across the schools. FGD discussants from Hashenege Kebele reported that iron and folic acid supplementation is provided only to pregnant women not for adolescents while the discussants from Hatsebo kebele mentioned it that the services has been provided but currently terminated. Despite the distribution of iodized salt, FGD discussants also raised that they do have doubt regarding its appropriate use.

Preventing Disease: On the other hand, participants frequently reported awareness creation interventions on preventing communicable diseases mainly water borne diseases, malaria, menstrual hygiene contraceptive use to preventing pregnancy, and sexually transmitted diseases like HIV/AIDS). Optimizing the use Insecticide Treated bed Net to prevent mosquito bite was the most frequently reported intervention.

They give us [ITN] every year in the month of in May and sometimes in September. At least they give us three ITN for one house hold per year to prevent mosquito bite [19 years, In-school, Lalay Maychew district].

However, participants mentioned that a long way is remained to ensure effective use of the ITN as they use the net for other purposes than the intended ones like to carry straw, cover straw, and some of the women use it to fasten their waist (as a belt). Awareness creation activities aimed to prevent water borne diseases was also raised,

We get support and health workers regarding safe drinking water. They advised us to boil and drink the water or to drink from tap water (14 years, In-school Tankua Abergele).

\section{Discussion}

Our study indicated that food insecurity among adolescents of the rural community of Tigrai was associated with limited access and availability of food due to shortage and seasonal variation of rainfall, and lack of farmland owning by youths. In parallel to this, almost all of the participants in our study claimed that stunting and anemia were among the commonest nutritional problems in pregnant women and adolescents. These nutritional problems may have a relationship with the food insecurity in the community, as it was similarly indicated by a study in China that food insecurity is associated with poor diet quality and unfavorable health outcomes, and significantly associated with malnutrition among 614 years of Chinese children [10]. Besides, it is indicated that food insecurity is a pervasive problem among adolescents from low-income communities and is associated with lower developmental assets [11]. Consequently, it is indicated that household food insecurity has strong linkage with adolescent 
school absenteeism [12]. Also, food insecure adolescents have a higher conditional probability of clinically significant psychological distress. Similarly, a cross-sectional, school-based data from the Global School-based Student Health Survey from 44 countries showed that food insecurity (hunger) is a global problem and is associated with suicide attempts [37]. This could be a clue that giving an attention by all concerned bodies to work at addressing food security of adolescents could be the way to secure a healthy bridge between childhood and adulthood of our generation.

One of the sustainable development goals for the 2030 agenda is mentioned to be, ensuring good nutrition requires access to safe water and sanitation [38]; however, as very repeatedly claimed by the respondents in our study, access to adequate and safe water is devastatingly problematic. Moreover, they stated that even the water they fetch traveling multiple hours of distance is not safe and adequate to meet the need for their domestic consumption. As a consequence, it is important to bear in mind that lack of access to clean water, and sanitation cause diarrhea and infectious diseases that interfere with the body's ability to absorb nutrients; because, unsafe water and food create a vicious cycle of diarrhea and malnutrition, threatening the nutritional status of the most vulnerable. [38]. And yet, the task of fetching water for households falls disproportionately to women and girls, especially in rural areas [39, 41]; consistent to this fact, in our study we found that adolescent girls are almost entirely involved in providing water to their households from very distant places (take up to three hours for single trip). Most of the participants in our study claimed that stunting and anemia are common among pregnant women and adolescent girls, though they projected different notions as causes for these burdens of nutritional problems in the community. Nevertheless, it may have a relationship to the vicious cycle of inadequate and unsafe water and food, as indicated by a cross-sectional study in India which depicted that Water, Sanitation, and Hygiene (WASH) practices may affect the growth and nutritional status among adolescents [42]. Besides, our study indicates that access to water for gardening is also almost absent that hindered them from producing and consuming nutritious foods like vegetables. In support of the interest of taking nutritious foods like vegetables by the respondents of our study, a cross-sectional evaluation from the USA showed that gardening experience is positively associated with F/V intake among college students [43].

Furthermore, in our study almost all the participants claimed also fetching water from distant places is one indication of their heavy workload as also supported by [44] that sucks their energy; lets them feel hunger, less concentrated at their academic performances. This is because water is heavy to carry [41]. Hence, their caloric expenditures, particularly during droughts, and other measures that affect health and quality of life must be considered [45]. This finding may give clue for the need of nutritional interventions focusing on multi-sectoral response, which may better address the demand for safe drinking water.

Despite the trend of adolescents' adherence to food taboo is getting weaker along time, avoiding eating of some available foods in resource limited settings, because for reasons related to foods taboo could significantly increase the risk of under-nutrition. Similar studies also recognized the effect of food taboo with nutritional problems [46-48], from a qualitative study explores that parental influence on eating behaviors in the perspective of the family's culture or religions as well as their habit play an important role 
in influencing food choice of adolescents [49]. In settings where food shortage is evident, presence of culturally backed food taboo among adolescents girls may implies that the relatively higher nutritional deficiency can persist.

\section{Conclusion}

A range of barriers hinder adolescent girls to access nutritional services. Food insecurity poses a strong challenge to adolescent girls' nutrition services. As access to safe drinking water continues to be a considerable bottleneck of for nutritional services, multi-sectoral response to integrate water sanitation and hygiene (WASH) services is required. Bounded by food taboo, high burden of workload and workloads among the adolescent girls, women empowerment and nutritional status seems to be the unfinished agenda in resource limited settings such as that of rural areas of Ethiopia.

\section{Declarations}

\section{Ethical approval and consent to participate}

The study was approved by the Institutional Review Board (IRB) of Mekelle University (Reference number: ERC 1113/2017) and permission to conduct the study was obtained from the Tigrai Regional State Health Bureau. Before the start of any data collection, participants were informed about their right to participate and refuse, as well as the purpose of the study and confidentiality of the information provided. Following this, verbal consent to participate was sought from each FGD and KIl participants.

\section{Consent for publication}

Not applied for this study

\section{Data availability statements}

The datasets used and/or analyzed during the current study are available from the corresponding author on reasonable request.

\section{Competing interest}

The authors declare that they have no any conflict of interest.

\section{Funding}

This research work is funded by the UNICEF and Tigrai Regional Health Bureau. But, these organizations had no role in the design, analysis, or writing of this article.

\section{Authors' contributions}


$\mathrm{AM}$ and $\mathrm{AH}$ designed the study and contributed to the development and implementation of the study. AK, $\mathrm{ZH}$, and DY collected raw data on the field. AK, HG, ZH, and DY conducted the analysis and interpretation of the data. AK, HG, and ZH drafted and finalized the manuscript. Besides, all the authors (mainly AM) contributed to editing and reviewing of the final manuscript. Finally, all authors read and approved the final manuscript.

\section{Acknowledgement}

Our gratitude goes to the study participants for their consent to participate and provision of invaluable information. We are also grateful to the UNICEF and Tigrai Regional Health Bureau for funding the project

\section{References}

1. Mulugeta A, Hagos F, Stoecker B, Kruseman G, Linderhof V, Abraha Z, et al. Nutritional status of adolescent girls from rural communities of Tigray, Northern Ethiopia. Ethiopian Journal of Health Development. 2009; 23(1).

2. Das JK, Salam RA, Thornburg KL., et al. Nutrition in adolescents: physiology, metabolism, and nutritional needs. Annals of the New York Academy of Sciences. 2017 Apr; 1393(1):21-33.

3. Gebremariam H, Seid O, Assefa H. Assessment of nutritional status and associated factors among school going adolescents of Mekelle City, Northern Ethiopia. Int. J. Food Sci. Nutr. 2015; 4:118-24.

4. UNICEF Staff. The state of the world's children 2011-executive summary: Adolescence an age of opportunity. Unicef; 2011.

5. DiMeglio G. Nutrition in adolescence. Pediatr Rev 2000; 21:32-8.

6. NCD Risk Factor Collaboration (NCD-RisC). Worldwide trends in children's and adolescents' body mass index, underweight, overweight and obesity, in comparison with adults, from 1975 to 2016: a pooled analysis of 2416 population-based measurement studies with 128.9 million participants. Lancet. 2017; 390(10113):2627-42.

7. Singla P, Sachdeva R, Kochhar A. Impact of nutrition counseling on consumption pattern of junk foods and knowledge, attitudes and practices among adolescent girls of working mothers. Journal of Human Ecology. 2012 Sep 1; 39(3):221-7.

8. Fanzo J, Hawkes C, Udomkesmalee E, Afshin A, Allemandi L, Assery O, et al. 2018 Global Nutrition Report: Shining a light to spur action on nutrition.

9. Central statistical agency (CSA) [Ethiopia] and ICF. Ethiopia demographic and health survey, Addis Ababa, Ethiopia and Calverton, Maryland, USA. 2016.

10. Shen X, Gao X, Tang W, Mao X, Huang J, Cai W. Food insecurity and malnutrition in Chinese elementary school students. British Journal of Nutrition. 2015 Sep; 114(6):952-8.

11. Shtasel-Gottlieb Z, Palakshappa D, Yang F, Goodman E. The relationship between developmental assets and food security in adolescents from a low-income community. Journal of Adolescent Health. 2015 Feb 1; 56(2):215-22. 
12. Tamiru D, Argaw A, Gerbaba M, Ayana G, Nigussie A, Belachew T. Household food insecurity and its association with school absenteeism among primary school adolescents in Jimma zone, Ethiopia. BMC public health. 2016 Dec; 16(1):802.

13. Kent MP, Pauzé E. The Frequency and Healthfulness of Food and Beverages Advertised on Adolescents' Preferred Web Sites in Canada. Journal of Adolescent Health. 2018 Jul 1; 63(1):102-7.

14. Tsarouhas K, Kioukia-Fougia N, Papalexis P, Tsatsakis A, Kouretas D, Bacopoulou F, et al. Use of nutritional supplements contaminated with banned doping substances by recreational adolescent athletes in Athens, Greece. Food and chemical toxicology. 2018 May 1; 115:447-50.

15. Giray C, Ferguson GM. Say yes to "Sunday Dinner" and no to "Nyam and Scram": Family mealtimes, nutrition, and emotional health among adolescents and mothers in Jamaica. Appetite. 2018 Sep 1; 128:129-37.

16. Watts AW, Miller J, Larson NI, Eisenberg ME, Story MT, Neumark-Sztainer D. Multicontextual correlates of adolescent sugar-sweetened beverage intake. Eating behaviors. 2018 Aug 1; 30:42-8.

17. Pearson N, Atkin AJ, Biddle SJ, Gorely T, Edwardson C. Patterns of adolescent physical activity and dietary behaviours. International Journal of Behavioral Nutrition and Physical Activity. 2009 Dec; $6(1): 45$.

18. Jongenelis MI, Scully M, Morley B, Pratt IS. Vegetable and fruit intake in Australian adolescents: Trends over time and perceptions of consumption. Appetite. 2018 Oct 1; 129:49-54.

19. Berg T, Magala-Nyago C, Iversen PO. Nutritional status among adolescent girls in children's homes: Anthropometry and dietary patterns. Clinical Nutrition. 2018 Jun 1; 37(3):926-33.

20. Gali N, Tamiru D, Tamrat M. The emerging nutritional problems of school adolescents: overweight/obesity and associated factors in Jimma town, Ethiopia. Journal of pediatric nursing. 2017 Jul 1; 35:98-104.

21. Parker KE, Salmon J, Brown HL, Villanueva K, Timperio A. Typologies of adolescent activity related health behaviors. Journal of science and medicine in sport. 2019 Mar 1; 22(3):319-23.

22. Thomas A, Janusek L. Obesity Prevention Behaviors in Asian Indian Adolescent Girls: A Pilot Study. Journal of pediatric nursing. 2018 Sep 1; 42:9-15.

23. Da Silva AO, Diniz PR, Santos ME, Ritti-Dias RM, Farah BQ, Tassitano RM, et al. Health selfperception and its association with physical activity and nutritional status in adolescents. Jornal de Pediatria (Versão em Português). 2019 Jul 1; 95(4):458-65.

24. Lee G, Han K, Kim H. Risk of mental health problems in adolescents skipping meals: The Korean National Health and Nutrition Examination Survey 2010 to 2012. Nursing outlook. 2017 Jul 1; 65(4):411-9.

25. Sormunen E, Saarinen MM, Salokangas RK, Hutri-Kähönen N, Viikari JS, Raitakari OT, et al. Body mass index trajectories in childhood and adolescence-Risk for non-affective psychosis. Schizophrenia research. 2019 Apr 1; 206:313-7.

26. Pereira JL, de Castro MA, Hopkins S, Gugger C, Fisberg RM, Fisberg M. Prevalence of consumption and nutritional content of breakfast meal among adolescents from the Brazilian National Dietary 
Survey. Jornal de Pediatria (Versão em Português). 2018 Nov 1; 94(6):630-41.

27. Bruckauf Z, Walsh SD. Adolescents' multiple and individual risk behaviors: Examining the link with excessive sugar consumption across 26 industrialized countries. Social Science \& Medicine. 2018 Nov 1; 216:133-41.

28. Chen JL, Guedes CM, Lung AE. Smartphone-based healthy weight management intervention for Chinese American adolescents: Short-term efficacy and factors associated with decreased weight. Journal of Adolescent Health. 2019 Apr 1; 64(4):443-9.

29. Philippou E, Middleton N, Pistos C, Andreou E, Petrou M. The impact of nutrition education on nutrition knowledge and adherence to the Mediterranean Diet in adolescent competitive swimmers. Journal of science and medicine in sport. 2017 Apr 1; 20(4):328-32.

30. Koniak-Griffin D, Anderson NL, Brecht ML, Verzemnieks I, Lesser J, Kim S. Public health nursing care for adolescent mothers: impact on infant health and selected maternal outcomes at 1 year postbirth. Journal of Adolescent Health. 2002 Jan 1; 30(1):44-54.

31. Tamiru D, Argaw A, Gerbaba M, Nigussie A, Ayana G, Belachew T. Improving dietary diversity of school adolescents through school based nutrition education and home gardening in Jimma Zone: Quasi-experimental design. Eating behaviors. 2016 Dec 1; 23:180-6.

32. Benny L, Boyden J, Penny M. Early is best but it's not always too late: Young Lives evidence on nutrition and growth in Ethiopia, India, Peru and Vietnam.

33. Rentería-Mexía A, Vega-López S, Olson ML, Swan PD, Lee CD, Williams AN, et al. Effects of a lifestyle intervention on markers of cardiometabolic risk and oxidized lipoproteins among obese adolescents with prediabetes. Public health nutrition. 2019 Mar; 22(4):706-13.

34. Seo YG, Lim H, Kim Y, Ju YS, Lee HJ, Jang HB, et al. The effect of a multidisciplinary lifestyle intervention on obesity status, body composition, physical fitness, and cardiometabolic risk markers in children and adolescents with obesity. Nutrients. 2019 Jan; 11(1):137.

35. World Health Organization. Adolescent nutrition: a review of the situation in selected South-East Asian countries. WHO Regional Office for South-East Asia; 2006.

36. Wassie MM, Gete AA, Yesuf ME, Alene GD, Belay A, Moges T. Predictors of nutritional status of Ethiopian adolescent girls: a community based cross sectional study. BMC Nutrition. 2015 Dec; $1(1): 20$.

37. Koyanagi A, Stubbs B, Oh H, Veronese N, Smith L, Haro JM, et al. Food insecurity (hunger) and suicide attempts among 179,771 adolescents attending school from 9 high-income, 31 middleincome, and 4 low-income countries: A cross-sectional study. Journal of affective disorders. 2019 Apr 1; 248:91-8.

38. World Health Organization. The state of food security and nutrition in the world 2018: building climate resilience for food security and nutrition. Food \& Agriculture Org.; 2018 Sep 12.

39. Bethany Caruso, 2017. Women still carry most of the world's water: [Nov25-2019], available at https://theconversation.com/women-still-carry-most-of-the-worlds-water-81054 
40. Bezabih A, Wereta M, Kahsay Z, Getahun Z, Bazzano A. Demand and Supply Side Barriers that Limit the Uptake of Nutrition Services among Pregnant Women from Rural Ethiopia: An Exploratory Qualitative Study. Nutrients. 2018; 10(11):1687.

41. De Moraes AF, Rocha C. Gendered waters: the participation of women in the 'One Million Cisterns' rainwater harvesting program in the Brazilian Semi-Arid region. Journal of cleaner production. 2013 Dec 1; 60:163-9.

42. Chattopadhyay A, Sethi V, Nagargoje VP, Saraswat A, Surani N, Agarwal N, et al. WASH practices and its association with nutritional status of adolescent girls in poverty pockets of eastern India. BMC women's health. $2019 \mathrm{Dec} ; 19(1): 89$.

43. Loso J, Staub D, Colby SE, Olfert MD, Kattelmann K, Vilaro M, et al. Gardening experience is associated with increased fruit and vegetable intake among first-year college students: A crosssectional examination. Journal of the Academy of Nutrition and Dietetics. 2018 Feb 1; 118(2):27583.

44. Saldanha LS, Buback L, White JM, Mulugeta A, Mariam SG, Roba AC, et al. Policies and program implementation experience to improve maternal nutrition in Ethiopia. Food and nutrition bulletin. 2012 Jun; 33(2_suppl1):S27-50.

45. Sorenson SB, Morssink C, Campos PA. Safe access to safe water in low income countries: water fetching in current times. Social science \& medicine. 2011 May 1; 72(9):1522-6.

46. Mohammed SH, Taye H, Larijani B, Esmaillzadeh A. Food taboo among pregnant Ethiopian women: magnitude, drivers, and association with anemia. Nutrition journal. 2019 Dec; 18(1):19.

47. Getnet W, Aycheh W, Tessema T. Determinants of Food Taboos in the Pregnant Women of the Awabel District, East Gojjam Zone, Amhara Regional State in Ethiopia. Advances in Public Health. 2018; 2018.

48. Zerfu TA, Umeta M, Baye K. Dietary habits, food taboos, and perceptions towards weight gain during pregnancy in Arsi, rural central Ethiopia: a qualitative cross-sectional study. Journal of Health, Population and Nutrition. 2016 Dec; 35(1):22.

49. Neumark-Sztainer D, Story M, Perry C, Casey MA. Factors influencing food choices of adolescents: findings from focus-group discussions with adolescents. Journal of the American dietetic association. 1999 Aug 1; 99(8):929-37. 